\title{
Enação e Metodologias de Primeira Pessoa: o reencantamento do concreto das investigações da experiência*
}

\section{Enaction and first-person methodologies: the reenchantment of the concrete of the investigations of experience}

\begin{abstract}
Resumo: Nos últimos vinte anos tem se ressaltado nas ciências cognitivas o interesse por metodologias de primeira pessoa para investigar a experiência. Queremos neste artigo interrogar o estatuto epistemológico dessas metodologias, a partir da abordagem da enação. Utilizaremos trabalhos de Varela e de comentadores de sua obra, como Evan Thompson e Antoine Lutz, sobre as metodologias de primeira pessoa. O reencantamento do concreto proposto por Varela para os estudos da cognição se coloca, a nosso ver, para as metodologias de primeira pessoa, a partir da abordagem pragmática da fenomenologia formulada por Depraz, Varela e Vermersch. Buscamos demonstrar que as metodologias de primeira pessoa, assim como toda atividade de conhecimento, possuem um caráter enativo. Palavras-Chave: Cognição. Experiência. Metodologias de primeira pessoa. Enação. Varela, Francisco.
\end{abstract}

Abstract: Over the last twenty years, cognitive sciences have emphasized the interest for first-person methodologies to investigate the experience. We want to question the epistemological status of these methodologies, from the approach of enaction. We use works of Varela and commentators of his work, as Antoine Lutz and Evan Thompson, on the first-person methodologies. The reenchantment of the concrete proposed by Varela to the study of cognition arises, in our view, to first-person methodologies, from the pragmatic approach of phenomenology formulated by Depraz, Varela and Vermersch. We show that the first-person methodologies, like all activity of knowledge, have an enactive dimension

Keywords: Cognition. Experience. First-person methodologies. Enaction. Varela, Francisco.

* Este artigo é baseado na tese de doutorado "Atenção a si: da auto-observação à auto-produção" defendida no Programa de Pós-Graduação em Psicologia da Universidade Federal do Rio de Janeiro-UFRJ em março de 2009, sob orientação da Profa Virgínia Kastrup (apoio de bolsa CNPq).

SADE, Christian. Enação e Metodologias de Primeira Pessoa: o reencantamento do concreto das investigações da experiência. Informática na Educação: teoria \& prática, Porto Alegre, v. 12, n. 2, p. 45-58, jul./dez. 2009.

\author{
Christian Sade \\ Universidade Salgado de Oliveira
}

\section{I ntrodução}

(O) campo das ciências cognitivas, desde o final dos anos oitenta, tem enfatizado o interesse pelo problema da consciência e da experiência, o que tem levado a uma reavaliação das teorias e métodos desse campo. Essa reavaliação tem apontado para a necessidade de se incluir nos estudos da cognição o uso de metodologias de primeira pessoa. A metodologia experimental padrão utilizada pelas ciências cognitivas, baseada em dados comportamentais e neuronais, não dá conta do domínio da experiência, na medida em que esta é definida como manifestação fenomenal, que é a noção de experiência em primeira pessoa (VARELA; THOMPSON; ROSCH, 1992, VARELA, 1996a, VARELA; SHEAR, 1999, LUTZ; THOMPSON, 2003, JACK; ROEPSTORFF, 2002, 2003, 2004, VERMERSCH, 1994, 1999, 2004, PETITMENGIN-PEUGEOT, 1999, 2006). Os processos cognitivos podem ser colocados em novas bases com as investigações de primeira pessoa, isto é, podem ser estudados não apenas como resultado observável de uma tarefa, mas também como um processo ou ação cognitiva que pode estar disponível como experiência consciente.

Distinguimos metodologias de primeira, segunda e terceira pessoa a partir do dispositivo utilizado para a coleta de dados 
e do tipo de dado coletado (VARELA; SHEAR, 1999, JACK; ROEPSTORFF, 2002 VERMERSCH, 1997). A metodologia de terceira pessoa é aquela em que o dado surge para o observador externo e científico, a partir de um dispositivo experimental. Ela pressupõe a relação do participante com um ambiente controlado. A metodologia de segunda pessoa é aquela na qual o dado surge para uma segunda pessoa, pela sua mediação. Ela pressupõe a relação do participante da pesquisa com esse outro sujeito, seja o pesquisador através das instruções para o experimento, seja um entrevistador através de perguntas ou questões. Já a metodologia de primeira pessoa é aquela na qual o dado é fenomenológico, no sentido daquilo que aparece para o sujeito, como experiência, a partir da atenção que o sujeito porta sobre si próprio, sobre isso que ele pode acessar de sua experiência no momento presente em que ele experimenta ou a posteriori (retrospectivamente). Ela pressupõe a relação do sujeito consigo mesmo em função de uma atenção a si.

Neste artigo queremos problematizar o estatuto epistemológico dessas metodologias de primeira pessoa, a partir da teoria da enação formulada por Francisco Varela. A abordagem da enação afirma que todo conhecimento é inseparável do sujeito cognoscente, sujeito e mundo constituem-se mutuamente, assim toda ciência cognitiva habita uma circularidade, na qual a cognição estudada não pode ser isolada da estrutura e experiência (corporificação) do sujeito. O problema que colocamos é: não seriam as próprias metodologias de primeira pessoa sujeitas ao mesmo problema da experiência, isto é, da corporificação da ação e constituição de si? Este é um ponto importante que a nosso ver não é devidamente levado em conta pelos autores que têm trabalhado com as metodologias de primeira pessoa. Os trabalhos de Varela e de seus comentadores acerca das metodologias de primeira pessoa nos oferecem subsídios para pensar que a exploração da experiência através de tais metodologias não visa um conhecimento objetivo (representacional) da experiência. Ainda que, a nosso ver, tais trabalhos não dêem o devido destaque a essa questão do caráter enativo das metodologias de primeira pessoa. Partindo da teoria da enação, visamos demonstrar que essa discussão sobre metodologias de primeira pessoa, tal como toda atividade de conhecimento, não é apenas epistemológica, mas é, sobretudo, ontológica.

\section{Abordagem Enativa: a dimensão ontológica do conhecer e o problema da experiência}

A abordagem da enação surge no campo das ciências cognitivas tentando fazer frente ao modelo da representação (VARELA, 1988, 1992, VARELA; THOMPSON; ROSCH, 1992). Pela abordagem representacional sujeito e mundo são dois entes pré-existentes. A relação cognitiva se assenta na recuperação ou representação de características ambientais extrínsecas eindependentes dosujeitocognitivo. Por outro lado, a abordagem da enação afirma que a cognição não é a representação de um mundo prévio por uma mente pré-existente, mas sim, a enação de um mundo e uma mente com base numa história de ações diversas realizadas pelo ser no mundo ${ }^{1}$.

Varela $(1989,1991,1997)$ define a cognição como essencialmente autônoma. A autonomia não é definida por um agente independente e pré-definido, e sim pela capacidade de redefinição constante dos limites nos quais opera a cognição. Autonomia implica a variação ou flexibilidade no centro da atividade cognitiva, sem a necessidade de um agente central. Se partíssemos de uma realidade completamente dada, a variação das situações compeliria a multiplicação das instâncias de controle responsáveis pela representação; precisaríamos sempre conhecer as leis do mundo para agir nele. Contudo, segundo Varela, Thompson e Rosch (1992), todas as nossas atividades dependem de um background que nunca pode ser precisado de forma absoluta e definitiva. Tarefas comuns, como cozinhar ou dirigir um automóvel, não são domínios dos quais é fácil especificar ou representar todos

1 O conceito de enação deriva do inglês to enact, que significa literalmente atuar, por em ato, efetuar. Varela (1988) pretende com ele preservar a proximidade entre ação e ator, ou seja, a ação está inevitavelmente ligada a um sujeito, mas este não existe independentemente dela (ser $=$ fazer). Ao mesmo tempo, a enação afirma que o conhecimento não depende unicamente de qualidades intrínsecas do que se conhece, pois este é en-agido, nós fazemo-lo emergir (ser $=$ fazer $=$ conhecer) 
os estados possíveis, seus limites são menos circunscritos ou mais indefinidos. Por isso, a “[ . . . ] maior habilidade da cognição viva [ . . . ] consiste na capacidade de colocar, dentro de amplos limites, os problemas relevantes que devem ser enfrentados a cada momento [ . . . ]" (VARELA; THOMPSON; ROSCH, 1992, p. 173). Tais questões “[ . . . ] não são predefinidas, mas en-agidas, nós fazemolas emergir [ . . . ]" (VARELA, 1988, p. 73). Tais limites indefinidos não pressupõem uma resposta verdadeiramente adequada, mas sim múltiplas possibilidades de enação de si e do mundo. A falta de fundamento absoluto na cognição é a urdidura da co-emergência, isto é: “. . . em saber como abrimos passo em um mundo que não é fixo e nem pré-dado, senão que se modela continuamente através dos atos que efetuamos [ . . . ]" (VARELA; THOMPSON; ROSCH, 1992, p. 173).

Essa compreensão enativa, contudo, não nos leva a um relativismo. O relativismo é um problema na epistemologia, pois ele pressupõe que as diferentes perspectivas do conhecimento são arbitrárias e, por isso, incomensuráveis. A teoria da enação mostra que o sujeito não é determinado por algo externo, um fundamento objetivo, entretanto, ele não atua de forma arbitrária no mundo. Como diz Varela, a realidade é dependente do sujeito da percepção, “ [. . . ] não porque ele a 'constrói' por um capricho [ . . . ]" (VARELA, 1992, p. 330), mas porque o que conta como mundo relevante é inseparável da sua incorporação. Varela, Thompson e Rosch (1992) criticam o que eles chamam de posição da galinha e do ovo. A posição da galinha é representacionalista, para ela o mundo externo tem propriedades pré-determinadas. Já a posição do ovo é solipsista, para ela o sistema cognitivo cria seu próprio mundo, cuja solidez aparente reflete as leis internas do sistema. A abordagem enativa critica ambas as posições: "Ainda que a mente e o mundo surjam juntos na enação, seu modo de emergir em qualquer situação particular não é arbitrário [. . . ]" (VARELA; THOMPSON; ROSCH, 1992, p. 207). Para a abordagem enativa a cognição não possui fundamento absoluto, tanto externo quanto interno, porém, isso não quer dizer que a cognição não possua suas condições de possibilidade. Tais condições de possibilidade existem, e elas são concretas, incorporadas, históricas e contextuais.
Para Varela (1992, 1996b), a cognição autônoma é essencialmente concreta, corporificada e situada. É a corporificação e o contexto, isto é, o concreto, que nos permite negociar nosso caminho em um mundo que não é fixo e pré-determinado. A maneira pela qual o sujeito é corporificado, e não algum mundo independente, é que especifica o modo como o observador pode agir e ser modulado pelos eventos ambientais. Varela afirma que a enação consiste não de representações, mas de ações corporificadas. Essa corporificação exprime uma perspectiva, em relação a qual, a atividade interpretativa da cognição se fará. Ou seja, o sujeito não entra em relação objetivamente com seu meio, mas sempre dependente de sua incorporação. É em função dela que o meio ganha uma qualidade singular para o cognoscente, torna-se um mundo próprio.

A corporificação é um processo que se dá na história de acoplamentos, na recorrência dos padrões sensório-motores. A enação é constituição de um corpo. É no próprio conhecer que o sujeito cognoscente é produzido (corporificado), conjuntamente ao objeto conhecido. É nesse sentido que a abordagem enativa é caracterizada por colocar em cena a gênese da realidade cognitiva, a base concreta ou incorporação a partir da qual co-emergem sujeito e mundo. Ela se contrapõe ao que Varela (1992) chama abordagem abstrata da cognição, dominante no campo das ciências cognitivas. A abordagem abstrata parte de uma relação sujeito-objeto já constituída. Seu problema é a representação do formal e do geral (abstrato). Nesse nível o mundo é dividido em domínios discretos, com seus elementos, propriedades e relações claramente definidos. O ponto cego da abordagem abstrata é justamente a gênese da realidade cognitiva. Varela ressalta que a forma de inteligência mais profunda e fundamental é a de um bebê, que adquire a linguagem a partir de emissões vocais diárias e dispersas, e delineia objetos significativos a partir de um mundo não especificado previamente. O concreto e o abstrato não se contrapõem, o abstrato é também concreto e este está na sua base.

Esse caráter concreto e incorporado da cognição coloca a questão da experiência no cerne do problema cognitivo. No trabalho em que Varela, Thompson e Rosch (1992) discutem a relação entre ciências cognitivas 
e experiência humana, eles afirmam que a corporificação possui uma dupla dimensão: ela remete ao corpo como realidade experiencial vivida e também ao corpo como o meio dos processos biológicos e cognitivos. Os processos cognitivos são inseparáveis de uma vivência, de uma apreensão fenomenal. Segundo Thompson (2004), na obra de Varela, essa inseparabilidade entre cognição e experiência está ligada a inseparabilidade entre mente e corpo. O corpo como coisa material (Körper) e o corpo como ser vivo e senciente (Leib) são dois modos de um único e mesmo corpo (THOMPSON, 2004). Para Thompson, essa unidade mente e corpo se encontra na obra de Varela desde a teoria da autopoiese, a qual afirma que o ser vivo é um ser cognitivo, isto é, um ser produtor de sentido, que constitui mundo e si a partir do acoplamento estrutural com o meio.

Varela (1998, VARELA; SHEAR, 1999) define experiência como manifestação fenomenal, fazendo referência ao trabalho de Thomas Nagel, What it is like to be a bat. A experiência consciente para Nagel (1981) significa que há alguma coisa que é like to be/like for um organismo. Este é o caráter subjetivo da experiência, afirma Nagel (1981), e ele é essencialmente ligado a um ponto de vista único (single). Por exemplo, eu posso conhecer a anatomia e a fisiologia de um morcego, posso descrever o seu padrão comportamental, mas eu não posso conhecer como é ser um morcego, a sua experiência, porque eu não posso ocupar o ponto de vista único que caracteriza o que é like to be/ like for um morcego. A experiência exprime a constituição de um mundo próprio, inerente à atividade cognitiva.

É a partir da experiência que surge a fronteira entre eu e mundo. Como manifestação fenomenal a experiência é sempre em relação a alguém, mas não de alguém, pois o sujeito não pré-existe à experiência, ele emerge a partir dela. Os sons e os odores que emergem, por exemplo, para um cão ou um morcego, não existem como tais, mas somente em relação a esses cognoscentes (VARELA, 1998). Os sons e os odores são para eles uma manifestação fenomenal, e nesse sentido são uma experiência, que Ihes dá uma perspectiva particular e, por isso, uma interface com o mundo, de onde a co-emergência sujeito e mundo (VARELA, 1991, 1998).

\section{Neurofenomenologia: em busca da circularidade entre cognição e experiência}

A abordagem padrão das ciências cognitivas parte da idéia de que a cognição se deve inteiramente às estruturas particulares dos sistemas cognitivos, as quais o cientista cognitivo busca representar através das pesquisas (VARELA; THOMPSON; ROSCH, 1992). Essa é uma abordagem abstrata, pois ela concebe a cognição como algo geral, formal e bem definida, isto é, representável. A cognição investigada pelas ciências cognitivas, seja através de experimentos de realização de tarefas, seja através da simulação computacional, é abstraída de atores específicos, de uma situação especifica. Em suma, ela é abstraída de sua concretude para se tornar uma estrutura geral e formal. Como mostra Vinciane Despret (2004), o ideal de conhecimento objetivo busca por em cena nas pesquisas a figura do qualquer um (quiconque). Qualquer um do lado do experimentador que, aplicando o protocolo de modo quase mecânico, deve poder reproduzir os mesmos resultados. Qualquer um do lado desses sujeitos anônimos, substituíveis, que vão entrar nas normas e curvas estatísticas. Não importa qual animal ou humano deverá reagir da mesma maneira, testemunhar de sua universalidade. O que a abordagem enativa nos leva a problematizar é que a cognição não pode ser reduzida a estruturas universais, presentes em qualquer um. Ela visa uma cognição encarnada, que é sempre uma emergência situada, em ato, singular e concreta.

No livro Embodied Mind, Varela, Thompson e Rosch buscam levar essa tendência rumo à corporificação nas ciências cognitivas (que Varela havia empreendido nos seus trabalhos sobre a teoria da enação) um passo além, na direção da corporificação como experiência vivida. Trata-se de considerar a circularidade intrínseca que existe nas ciências cognitivas: o estudo dos fenômenos mentais é sempre aquele de uma pessoa experienciando (experiencing person). As ciências cognitivas são um projeto inerentemente circular. Como toda ciência ela é uma prática humana, mas, é uma prática distinta, pois ela se volta para nós mesmos para fazer de nossa cognição um tema científico. As ciências cognitivas de abordagem abstrata/ 
representacional tentam evitar ou neutralizar essa circularidade, isolando o fenômeno do conhecer da explicação do conhecer. Contudo, do ponto de vista da enação essa circularidade é fundamental, e o problema é: como nos situar apropriadamente no interior dela? As teorias sobre a cognição não podem ser isoladas da experiência, do contexto, em suma, da incorporação do cientista cognitivo. Daí a necessidade de se promover a circularidade entre ciência e experiência humana (VARELA; THOMPSON; ROSCH, 1992, THOMPSON, 1996, VARELA; SHEAR, 1999).

A proposta lançada em Embodied Mind é prolongada no projeto chamado Neurofenomenologia (VARELA, 1996a). Este visa à investigação sistemática da experiência de um evento cognitivo, de modo a fornecer categorias experienciais capazes de serem postas em relação, ou em circulação, com as categorias neurocientíficas e comportamentais. Esta é a hipótese de trabalho da Neurofenomenologia: iluminação recíproca ou constrangimentos mútuos entre as descrições neurodinâmicas e aquelas relativas à experiência. A Neurofenomenologia visa retomar esse caráter concreto e corporificado da cognição, em sua dupla dimensão: experiência e estrutura/processo. A idéia dessa iluminação recíproca, partindo da inseparabilidade entre essas dimensões, é que uma boa investigação da experiência orienta uma boa pesquisa cerebral, e esta por sua vez, nos põe boas questões para a investigação da experiência. O foco da Neurofenomenologia é o processo (temporal) de corporificação da ação, ou seja, descrever e correlacionar as variações tanto da experiência quanto das respostas comportamentais e/ou neuronais durante a realização de um experimento.

Um exemplo da proposta Neurofenomenológica é o estudo piloto ( LUTZ; LACHAUX et al., 2002, LUTZ; THOMPSON, 2003, THOMPSON; LUTZ; COSMELLI, 2005) que investigou a correlação das variações na experiência subjetiva com os dados da neuro-imagem para uma tarefa de percepção ilusória em três dimensões. Nesse experimento os sujeitos eram apresentados a um padrão de pontos aleatórios, no qual eles deviam se fixar por alguns segundos. Os sujeitos deviam apertar um botão tão logo uma imagem em três dimensões houvesse emergido completamente. O tempo de reação ao apertar o botão era registrado. Ao longo do teste sua atividade cerebral era mapeada através de um eletroencefalograma (EEG). Imediatamente após acionar o botão os sujeitos davam um breve relato verbal sobre a sua experiência. Nesse relato eles descreviam suas experiências usando categorias fenomenais que eles haviam discriminado durante a sessão de treinamento, anterior ao experimento propriamente dito. O objetivo da sessão de treinamento era melhorar a discriminação perceptual dos sujeitos e capacitá-los a explorar cuidadosamente as variações da sua experiência subjetiva durante repetidas exposições à tarefa. Para isso, eles eram instruídos a direcionar a sua atenção para os seus próprios processos mentais durante a tarefa e sentir a qualidade da emergência da imagem em três dimensões. Dessa forma, o experimento envolvia a coleção simultânea de dados de primeira pessoa (relatos verbais introspectivos/retrospectivos) e de dados de terceira pessoa (registros eletrofisiológicos e medidas comportamentais de tempo de reação).

Os relatos verbais descritivos da experiência dos sujeitos foram agrupados de acordo com fatores comuns a respeito do grau de preparação sentido pelos sujeitos e da qualidade da percepção sentida na emergência da imagem em 3D. Foram formuladas então três categorias: prontidão estável (Steady Readness), prontidão fragmentada (Fragmented Readness) e despreparado (Unreadness). A hipótese era que essas distintas características da experiência subjetiva estariam correlacionadas com distintos sinais da dinâmica neural. No estado de prontidão estável os sujeitos relataram estar bem preparados para a apresentação do estímulo, com uma sensação de continuidade quando a estimulação ocorreu e uma impressão de fusão entre ele e o percepto em 3D. Corroborando a hipótese, os registros da atividade cerebral mostraram uma estável sincronização do conjunto neural que era mantida ao longo do teste, correlacionando com a impressão subjetiva de prontidão e de continuidade; neste caso o tempo de reação foi rápido (300 ms em média). Por sua vez, no estado despreparado os sujeitos relataram estar distraídos e tendo uma forte sensação de descontinuidade no fluxo de seus estados mentais. Quando o estímulo (imagem 3D) foi apresentado, eles descreveram uma clara impressão de diferenciação entre 
eles e o percepto. Também corroborando a hipótese, no estado despreparado nenhuma sincronização estável pode ser distinguida na média, e quando a emergência da imagem em 3D ocorreu revelou-se uma fraca sincronização e massiva dessincronização entre as áreas frontais e posteriores do cérebro. Essa descontinuidade da dinâmica cerebral foi correlacionada com a impressão subjetiva de descontinuidade. Além disso, neste caso o tempo de reação foi mais longo (600 ms na média). Lutz e Thompson (2003) extraem três conclusões dessa pesquisa: a) os dados sobre o contexto subjetivo podem ser correlacionados aos padrões de sincronização medidos pelo EEG; b) os estados de preparação e percepção modulam as repostas comportamentais $e$ neurais após o aparecimento da figura em 3D; c) esses dados da experiência ajudam a tornar inteligíveis as respostas neurais.

Varela (1996a) propõea Neurofenomenologia como uma solução metodológica para o hard problem formulado por David Chalmers. Em meados dos anos noventa, Chalmers (2004) define que o desafio do projeto de construção de uma ciência da consciência é investigar a relação entre os problemas fáceis e difíceis da consciência. O problema fácil da consciência (fácil porque é mais bem conhecido ou explicado) é referido aos mecanismos funcionais objetivos da mente (cerebral na verdade) que lhe permitem discriminar estímulos, integrar informações, produzir relatos verbais e controlar o comportamento. Já o problema difícil é referido à experiência subjetiva, ao modo como as coisas são percebidas pelo indivíduo, como elas lhe aparecem, à dimensão qualitativa da experiência associada aos fenômenos cognitivos. Chalmers (2004) afirma a irredutibilidade da experiência aos dados de terceira pessoa e por isso para ele a integração desses diferentes dados depende da construção de outro modelo explicativo. Este deve integrá- los através de sistemáticos bridgin principles, conceitos extras que fundamentem e expliquem a co-variação entre os dados de terceira pessoa e os dados de primeira pessoa. Chalmers (2004) parte da separação entre as dimensões estruturais e objetivas da cognição e sua dimensão qualitativa e vívida, assim surge todo o problema de como colocálas em relação. Para Chalmers a experiência consciente permanece um mistério ou uma questão difícil na medida em que há fatos nela que não podem ser deduzidos dos fatos físicos relativos ao funcionamento do cérebro, e nesse sentido só lhe resta perguntar: “[ . . . ] por que a realização dessas funções é acompanhada pela experiência consciente?" (CHALMERS, 2004, p. 45).

Lutz e Thompson (2003, THOMPSON, 2004) vêem nesse projeto da Neurofenomenologia uma resposta não ao hard problem formulado por Chalmers, mas uma resposta ao que eles chamam explanatory gap. O hard problem é um problema metafísico para eles, ao passo que o explanatory gap é um problema epistemológico e metodológico. O hard problem é um problema metafísico e abstrato sobre o lugar da consciência na natureza, a pergunta que o define é como é possível derivar a experiência subjetiva da natureza física objetiva. Já o explanatory gap é um problema epistemológico que, partindo da não separação entre experiência e cognição, pergunta como por em relação os relatos de primeira pessoa acerca da experiência com os relatos estruturais neurocognitivos. Segundo Lutz e Thompson (2003), a Neurofenomenologia não visa fechar o gap no sentido de uma redução ontológica, sua proposta é transpor o gap num nível metodológico, estabelecendo iluminação recíproca entre as descrições de primeira e terceira pessoa.

Para Varela (1996a), a abordagem de Chalmers ainda é abstrata. A Neurofenomenologia tem pouco a ver com alguma teoria ou conceito extra. Varela concebe o caráter irredutível da experiência pela perspectiva de primeira pessoa, ou seja, a experiência é irredutível a qualquer posição que não tome a experiência nela mesma. Daí a sua defesa de que a experiência deve ser explorada através de um método de primeira pessoa. O problema da abordagem abstrata é que ela toma a experiência de um ponto de vista externo a ela mesma. Este é o problema das reflexões filosóficas e científicas no ocidente a respeito da experiência, afirmam Varela, Thompson e Rosch (1992). Por isso, eles destacam as tradições orientais de meditação. No budismo, os comentários e as descrições sobre a mente nunca se divorciaram de uma pragmática da vida. Não existe conhecedor abstrato de uma experiência que seja separado da própria experiência. A pergunta o que é a mente? jamais se torna desincorporada, abstrata, no budismo. "Quando em nossa reflexão 
acerca de uma pergunta incluímos aquele que formula a pergunta e o processo de formulála (recordemos a circularidade fundamental), a pergunta recebe nova vida e significado [ . .. ]" (VARELA; THOMPSON; ROSCH, 1992, p. 56).

No livro Embodied Mind, Varela, Thompson e Rosch (1992) dão um exemplo de iluminação recíproca. Eles apresentam a convergência entre o conhecimento da experiência oriundo da meditação budista e o conhecimento das ciências cognitivas a respeito da fragmentação do eu (self), além da convergência entre o budismo e a abordagem enativa sobre a relação não dual entre sujeito e mundo. O recurso a tradição budista é justamente para mostrar como estes conhecimentos das ciências cognitivas não estão necessariamenteapartados da experiência cotidiana das pessoas, baseada na crença em um eu sólido e independente. A questão era mostrar como a experiência, a partir de uma exploração metódica, pode convergir com os conhecimentos da ciência cognitiva.

Essa mudança da experiência, no entanto, coloca um problema: podemos ou não afirmar que a experiência apresentada pelas técnicas de meditação budista é mais (ou menos) real que a experiência de um eu sólido? E no caso da Neurofenomenologia, cujo uso das metodologias de primeira pessoa visa acessar a dimensão corporificada e processual da experiência, que é em grande parte tácita e pré-refletida, tais metodologias permitiriam um acesso objetivo a essa experiência? Se Varela lança a proposta de inclusão das metodologias de primeira pessoa pelas ciências cognitivas para promover a circularidade entre ciência e experiência (corporificação da cognição), ele não pode evitar a circularidade no interior destas próprias metodologias, sob o risco de que elas tenham um caráter representacional. A nosso ver, este é um ponto que não é devidamente levado em conta por Varela e seus comentadores. Torna-se necessário, então, apresentar o caráter enativo das metodologias de primeira pessoa.

\section{Enação e Metodologias de Primeira Pessoa: da auto- observação à auto-produção}

Lutz e Thompson (2003) definem os métodos de primeira pessoa como práticas disciplinadas que os sujeitos podem usar para aumentar a sua sensibilidade a sua própria experiência gradualmente. Essas práticas envolvem sistemático treinamento da atenção e da auto-regulação emocional. Essa definição de metodologias de primeira pessoa é fundamentada, na tradição da fenomenologia, da meditação budista, da psicoterapia (DEPRAZ; VARELA; VERMERSCH, 2003, VARELA; SHEAR, 1999). A relevância dessas tradições para a Neurofenomenologia é a capacidade para uma auto-consciência (self-awareness) atenta que elas sistematicamente cultivam. Essa capacidade possibilita que aspectos pré-verbais e pré-refletidos da experiência subjetiva, que de outra forma permaneceriam tácitos, possam tornar-se subjetivamente acessíveis e descritíveis. Assim como na redução fenomenológica, o problema metodológico da Neurofenomenologia é redirecionar a atenção para a fonte dos processos mentais, para o que está emergindo como objeto/conteúdo, e não para o objeto em si (VARELA, 1996a, LUTZ; THOMPSON, 2003, THOMPSON; LUTZ; COSMELLI, 2005).

Lutz e Thompson (2003) citam três desafios enfrentados pelas metodologias de primeira pessoa: 1) os relatos de primeira pessoa podem ser parciais ou não acurados; 2) o processo introspectivo pode modificar a experiência visada; 3) como relacionar a experiência subjetiva aos processos fisiológicos e comportamentais. Esse terceiro desafio é solucionado pela Neurofenomenologia com a resposta ao explanatory gap. Já em relação aos dois primeiros, Lutz e Thompson afirmam que o aumento da sensibilidade do sujeito a sua própria experiência, promovido pelas metodologias de primeira pessoa, intensificam a auto-consciência de modo que tais métodos tornam-se menos intrusivos, mais estáveis e espontâneos. Dessa forma, os métodos de primeira pessoa podem gerar relatos descritivos mais refinados e estáveis, características necessárias para que eles possam ser compartilhados intersubjetivamente e postos em relação com os dados comportamentais e cerebrais. 
Essa noção de relatos descritivos mais estáveis e refinados, porém, não pressupõe relatos mais acurados. Tendo em vista afirmações sobre o caráter plástico e mutável da experiência, não parece, a nosso ver, que na Neurofenomenologia o problema das metodologias de primeira pessoa seja a acurácia das descrições sobre a experiência. Segundo Lutz e Thompson (2003, p. 39): "Qualquer um que já adquiriu uma habilidade cognitiva nova (como a fusão estereoscópica, degustador de vinho, ou uma segunda linguagem) pode atestar que a experiência não é fixa, mas dinâmica e plástica [ . . . ]". Eles afirmam a respeito do aumento da sensibilidade à própria experiência promovida pelas metodologias de primeira pessoa: “[ . . . ] tal desenvolvimento implica que a experiência está sendo treinada e reformada [ . . . ]" (LUTZ; THOMPSON, 2003, p. 47). E completam afirmando que necessariamente não há qualquer inconsistência entre alterar e transformar a experiência (do modo visado) e ganhar insight sobre a experiência através de tal transformação. Como dizem Lutz e Thompson (2003), essa crítica sobre a parcialidade e falibilidade das metodologias de primeira pessoa pressupõe o acesso a uma experiência pura, estática, não treinada.

Mas, como afirmam Varela (1996a) e Thompson (1996), não há um ponto de vista independente e externo à experiência que permite determinar o que conta como experiência real ou normal (mais uma vez a circularidade fundamental). "Experiência não é objetificável: qualquer reflexão sobre a experiência é ela mesma uma forma de experiência que não deixa a experiência imutável [ . . . ]" (THOMPSON, 1996, p. 140). Por sua vez, Varela afirma: “[ . . . ] experiência parece ser inerentemente sem limites e flexível, e daí não há qualquer contradição em dizer que treinamento sustentado em um método pode tornar disponíveis aspectos da experiência que não estavam disponíveis antes [ . . .]" (VARELA, 1996a, p. 346). Assim como a cognição enativa, a experiência não é objetificável. Neste caso, perguntas como: que formas a experiência pode assumir (a partir de um método de exploração)? São mais adequadas do que: como pode a experiência derivar do cérebro? Ou mesmo: o que é a experiência (em si)? A Neurofenomenologia busca, a partir de um exame empírico, verificar que formas podem assumir a correlação mente e corpo. Ela não parte de uma representação do que é a mente e do que é o corpo, para então responder como elas se relacionam. A nosso ver, esta é uma abordagem pragmática, como é afirmado por Varela e Shear:

[. . .] experiência humana não é um domínio fixo e prédeterminado. Ao invés disso, ela é mutante, mutável e fluida. Se alguém sofrer um treinamento disciplinado em performance musical, as novas habilidades adquiridas de distinção de som, de sensibilidade às expressões musicais e ao conjunto musical, são inegáveis. [ . . . ] Tudo o que nós temos é experiência no seu próprio nível de exame, e dependendo dos tipos de esforços e métodos empregados. Ela move e muda, e sua exploração é já parte da vida humana, embora geralmente com outros objetivos que compreender a experiência mesma [. . .] (VARELA; SHEAR, 1999a, p. 14).

O aumento da sensibilidade da experiência a si própria, o “. . . despertar da experiência para si própria . . ." como definem Lutz e Thompson (2003, p. 47), não visa acessar uma experiência pura e independente, mas sim estabilizar sua plasticidade e traduzir a experiência em relatos descritivos mais precisos, que possam ser colocados em relação com os dados de terceira pessoa. Há uma aparente contraposição: não há experiência estática a ser acessada, ao mesmo tempo em que se busca estabilizar a experiência e obter relatos mais precisos que possam ser corroborados intersubjetivamente, como se fossem representações objetivas da experiência. Mas o que a abordagem pragmática de Varela e Shear (1999) nos leva a pensar é que essas categorias descritivas, por mais estáveis e precisas que sejam, não podem ser vistas como representações da experiência, pois, a experiência acessada e descrita não existe independente dos esforços e métodos empregados, independente do observador, que co-emerge com ela assim como o músico co-emerge com a experiência musical $^{2}$. É nesse sentido que, a nosso ver, as metodologias de primeira pessoa, ainda que visem acessar e relatar categorias refinadas e precisas da experiência, o que implicaria um processo (representacional) de autoobservação, implica de fato um processo de

2 A esse respeito é interessante a observação de Velmans (1999), problematizando a dicotomia entre investigação subjetiva $x$ investigação objetiva: os fenômenos são objetivos no sentido de que eles são intersubjetivos, assim como os procedimentos são objetivos na medida em que são bem especificados e então realizáveis por todos, contudo, eles não são objetivos no sentido de independentes do observador; e isso se aplica tanto aos estudos da consciência quanto à física. 
auto-produção. Esta questão nos permite afirmar que as metodologias de primeira pessoa não se confundem com inspeção privada, com conhecimento de um eu interno e pré-existente.

A crítica feita por Varela, Thompson e Rosch (1992) à introspecção da psicologia do final do século XIX problematiza a relação sujeitoobjeto estabelecida nela. No introspeccionismo clássico era pedido ao sujeito que olhasse para sua própria experiência como um observador externo o faria, mantendo a separação sujeito-objeto, o que Varela, Thompson e Rosch chamam de atitude abstrata do introspeccionista em relação a sua mente. Essa atitude abstrata implica a imposição de um quadro interpretativo separado da experiência. Os elementos sensoriais independeriam da incorporação do pesquisador e da situação concreta do experimento. Varela (1996a) afirma que os relatos da introspecção clássica eram muito influenciados pelos fundamentos teóricos dos estudos, e, rapidamente caíam em argumentos de autoridade. Mas, essa recusa da introspecção clássica não se faz pela sua falta de acurácia ou de objetividade, pelo contrário, se faz pela sua atitude abstrata, ao visar um conhecimento representacional da experiência. É em relação a essa escolha, que consideramos relevante ressaltar o caráter não dual (enativo) das metodologias de primeira pessoa, o que implica uma abordagem pragmática. Essa abordagem nos põe o desafio de avaliar o conhecimento não pela sua objetividade, mas, sobretudo pelas formas concretas, emergências encarnadas, que ele pode assumir, o que coloca uma questão éticopolítica (VARELA, 1996b).

Essa abordagem pragmática das metodologias de primeira pessoa foi desenvolvida por Depraz, Varela e Vermersch $(2003,2006)$ com a proposta de uma fenomenologia pragmática. Varela (1996a) encontra na redução um método sistemático para explorar de forma disciplinada a experiência. Varela propõe assim um uso da redução no interior das ciências cognitivas, como uma fonte de dados empíricos de primeira pessoa. Mas, isso implica investir na fenomenologia como uma prática, possível de ser operada por um agente concreto numa situação de pesquisa. Esse investimento ele propõe num trabalho conjunto com Natalie Depraz e Pierre Vermersch $(2003,2006)$. Eles afirmam que Husserl não abordou a redução como um método concreto, ressaltando as dificuldades e obstáculos na sua realização. Como faz, por exemplo, o budismo com a meditação. É isso que Depraz, Varela e Vermersch (2003, 2006) buscarão com a proposta de uma fenomenologia pragmática. Eles buscam descrever como o método da redução é corporificado por um sujeito, ao invés de ser apenas uma interpretação ou compreensão teórica do trabalho de Husserl:

[...] a fenomenologia reivindicada aqui se caracteriza por seu funcionamento concreto, sua dimensão operatória, processual ou performativa, logo, sua práxis, muito mais do que por sua sistemática teórica interna, sua visada de conhecimento e de justificação a priori e apodíctica dos conhecimentos. (DEPRAZ; VARELA; VERMERSCH, 2006, p. 77)

Num trabalho intitulado Redução Fenomenológica Como Práxis", Natalie Depraz afirma:

É importante perguntarmos para nós mesmos hoje novamente em que medida o gesto de redução não é simplesmente um método formal tornando possível uma análise teórica, [ . . . ] mas é totalmente enraizado numa práxis efetiva que produz acesso intuitivo à experiência interna. (DEPRAZ, 1999, p. 97)

Nessa abordagem pragmática, descrever a redução é inseparável de sua efetuação. Nesse sentido, não se trata de descrever uma teoria baseada em argumentos a priori sobre a redução, mas sim de se engajar numa lógica exploratória, em que se descobre o que se relaciona com a questão a partir de sua práxis. Segundo Depraz, Varela e Vermersch (2003), o conceito aristotélico de práxis corresponde a uma atividade imanente, que contém nela mesma seu próprio fim, e não precisa de um esquema preparado. Já o conceito marxista de práxis, de acordo com os mesmos autores, corresponde à atividade humana, às transformações materiais e sociais da natureza e da sociedade, pelo qual o processo mesmo de conhecimento e de teorização é incluído no interior de uma apropriação prática pelo mundo e pelo eu (self). Os autores também afirmam que a práxis implica mudança do mundo e de si mesmo pela ação concreta. Dessa forma, com Marx, o mito de um conhecimento puramente contemplativo ou representacional desaparece, já que toda teoria tem sua própria dinâmica baseada numa prática, mesmo no caso de uma prática teórica.

A teoria da enação também fundamenta essa abordagem pragmática: “[ . . . ] o que imediatamente nos leva ao coração do método privilegiado neste trabalho: descrever 
- processo de devir consciente a partir de sua própria enação, descrevê-lo como ele é realizado [ . . . ]" (DEPRAZ; VARELA; VERMERSCH, 2003, p. 155). Eles destacam na enação o fato de que a cognição é sempre assentada numa ação concreta e corporificada: “O mundo não é algo que é dado a nós: ele é algo no qual nos engajamos pelo modo como movemos, tocamos, respiramos e comemos [ ... .]" (DEPRAZ; VARELA; VERMERSCH, 2003, p. 156). A atividade cognitiva não depende das formas simbólicas abstratas: não basta conhecer as regras da gramática para operar a produção de sentenças, assim como não basta conhecer as regras acerca de como se anda de bicicleta para andar de fato de bicicleta. Ambas as atividades dependem de um saberfazer, de uma corporificação da ação por parte do sujeito. A redução é uma prática e sua efetuação não pode ser aprendida nos livros, não se prestando a uma aprendizagem teórica ou simbólica (KASTRUP, 2004). Realizar uma pesquisa, do ponto de vista metodológico, não se resume a conhecer e obedecer às regras de um protocolo, pois a realização concreta deste depende de como ele é efetivamente posto em ato (enagido) pelo sujeito, de como ele é encarnado. É esta mesma questão, que, pela abordagem enativa, leva a necessidade de incluir uma metodologia de primeira pessoa nos estudos da cognição, que estamos destacando no interior das próprias metodologias de primeira pessoa.

Essa abordagem pragmática da redução feita por Depraz, Varela e Vermersch (2000, 2003) visa a redução não apenas como um método para se explorar a experiência, mas, como sendo a sua práxis ela mesma uma experiência. E ao se operar a redução, essa experiência se apresenta como um processo de devir da consciência. É no interior dessa questão do devir consciente - “[ . . . ] retomar as diferentes etapas do processo pelo qual advém à minha consciência clara alguma coisa de mim mesmo que me habitava de modo confuso e opaco, afetivo, imanente, logo, pré-refletido [ . . . ]" (DEPRAZ; VARELA; VERMERSCH, 2006, p. 77) - que os autores descreverão a prática da redução. Mas, sendo assim, a própria questão do devir consciente não comporta resposta a priori, depende de uma práxis efetiva. Eles afirmam, assim como Varela e Shear (1999), que a linha divisória entre consciência e inconsciente não é fixa e pré-definida, ela é móvel, e dependente dos métodos de exploração. Depraz, Varela e Vermersch (2003) fornecem então exemplos de diferentes práticas em que se realizam diferentestomadas deconsciência: introspecção guiada (entrevista de explicitação), Shamatha (sessão de meditação), visão estereoscópica, oração do coração (tradição ortodoxa), sessão de psicanálise, sessão de escrita, início de curso de filosofia. Em todos esses domínios e tradições a prática é fruto de um engajamento coletivo, de uma corporificação por parte de uma comunidade.

Depraz, Varela e Vermersch (2003) extraem dessas práticas uma estrutura geral do processo de tomada de consciência. Eles apresentam essas práticas como exemplos situados e corporificados dessa estrutura geral. Essa estrutura descreve o próprio gesto de redução, e é chamado ciclo básico. Ela é constituída por três fases entrecruzadas. Uma etapa de suspensão da atitude natural, atitude judicativa com a qual normalmente nos voltamos para o mundo, e que caracteriza uma atitude de controle. Uma segunda etapa de redireção da atenção do exterior para o interior. E uma terceira etapa de mudança da qualidade da atenção, de acolhimento da experiência, chamada deixar-vir (lacher prise).

O uso da redução para investigar a experiência requer uma incorporação dessas três fases. Mas, tais gestos são contraintuitivos, eles sofrem resistência de nossa consciência cotidiana, marcada pela atitude natural. Sendo assim, podemos afirmar que a prática da redução possui efeitos constitutivos de si. Depraz, Varela e Vermersch (2003, p. 26) afirmam: "Husserl permanece ligado à busca pelo conhecimento e não produz uma ética como tal, entretanto, a ênfase na atitude de suspensão pode ser interpretada como um ethos geral da vida e conhecimento". E num outro trecho eles acrescentam, afirmando acerca da prática do ciclo básico:

[. . .] é aprender a praticar a relação consigo mesmo, aprender a escutar a si mesmo, aprender o deixar-vir que supõe a aceitação do preenchimento não imediato que sempre segue ao gesto de suspensão. [ . . . ] a prática de atender a sua experiência subjetiva implicará a sua pessoa inteira, desde que será uma questão de trabalhar sobre a sua própria auto-relação, sobre os detalhes de sua própria experiência. (DEPRAZ; VARELA; VERMERSCH, 2003 p. 101)

A suspensão e a redireção da atenção pressupõe a saída de uma posição de controle, 
mais voltada para o agir e a vida prática. Na atitude natural nossa atenção está voltada para a vida prática. Ela se engaja na percepção dos outros, na apreensão de informações provenientes do mundo, na busca de objetivos. Como diz Depraz, Varela e Vermersch (2003, 2006), a atenção é naturalmente interessada no mundo, ela não se desvia dele espontaneamente de forma alguma, pois o efeito de captação é irresistível. Essa atenção direcionada para si, e desviada ou desinteressada do mundo, é muito inabitual, na medida em que há relativamente poucas ocasiões de exercê-la espontaneamente ou em resposta a uma demanda educativa. Ainda segundo eles, a teoria de Piaget sobre a abstração refletinte havia demonstrado a pregnância sobre a atenção das informações positivas, isto é, das informações diretamente perceptíveis em sua presença material a mim. A atitude de controle também está ligada ao engajamento na ação. Para quem é iniciante, e não está acostumado com a prática de voltar a atenção para si é preciso suspender o investimento no agir. Esse não agir é no princípio literal, permanecer em uma posição sentada, em uma atitude de escuta atenta, ou ainda deitado no divã. É por isso que segundo Depraz, Varela e Vermersch (2003, 2006), essa ênfase na idéia de suspensão da atitude de controle conduz ao uso de uma linguagem que é aquela do relaxamento, da entrega ou do deixar-vir (lacher-prise).

A redireção da atenção não visa comentários ou imagens internas, ele se volta para a fonte dos processos mentais, para o que está emergindo como objeto/conteúdo, e não para o objeto em si. Não se trata de atentar para a primeira coisa que vem à cabeça, ou aquilo que é imediatamente consciente. Essa é uma questão importante tendo em vista a pregnância das informações positivas sobre a atenção. De acordo com Depraz, Varela e Vermersch (2003, 2006), Husserl concebe essa redireção ou conversão da atenção como uma mudança de atitude na relação que eu entretenho com o mundo, no sentido de uma conversão do interesse natural dedicado ao objeto, em direção ao ato que me permite acessá-lo. É assim que se coloca o movimento mesmo da redução fenomenológica como conversão do objeto ao ato, ou como passagem da coisa (quod) ao modo dela (quomodo). Já a mudança da qualidade da atenção, e a atitude de deixar vir pressuposta por ela, é definida pela manutenção da tensão entre um ato de atenção sustentada e um não preenchimento imediato. Há uma espera sem conhecimento do conteúdo que vai se revelar, o que é diferente da atitude do caçador imóvel, o caçador paciente e vigilante sabe o que ele espera. Essa atitude do deixar vir supõe uma espera não focalizada e por isso aberta, normalmente descrita como ausente de alguma discriminação imediata, como não há nada, é uma névoa, é confuso.

Apesar de Depraz, Varela e Vermersch (2003) descreverem um ciclo básico comum aos diferentes settings citados, a nosso ver, é importante destacar como ele é encarnado de forma diferente e enseja diferentes experiências em cada um desses contextos. Neste caso, talvez seja importante ressaltar como o ciclo básico se apresenta concretamente de forma diferente em cada um dos settings, conforme descrição dos autores. Os suportes para a redireção da atenção variam em cada caso. $\mathrm{Na}$ Samatha esse suporte pode ser manter a atenção na respiração ou numa imagem mental. Na entrevista de explicitação é buscar um passado concreto e singular. No curso de filosofia é o encontro com um obstáculo interno, que nos faz manter continuamente a atenção sobre a questão. Na oração do coração é a dificuldade para conciliar o fio da oração com o da respiração (a oração consiste em dizer Senhor J esus Cristo durante a inspiração, e tende piedade de nós durante a expiração).

Também a mudança da qualidade da atenção apresenta diferentes modalidades. Na entrevista de explicitação ela é apresentada como uma diminuição do ritmo da fala. Na oração do coração como a contemplação dos pensamentos à distância. Na sessão de psicanálise e na pesquisa filosófica como a espera por um sentido. No Samatha avançado como a intensificação e estabilização da atenção. Neste caso, sustentar a atenção na respiração, acompanhado do gesto de suspensão, pode nos levar a sentir uma intensificação e clareza da experiência (WALLACE, 1999, 2008), ou uma amplitude da mente (VARELA; THOMPSON; ROSCH, 1992), na qual a fronteira entre interno e externo se apagam. Na entrevista de explicitação, o sujeito começa a sentir que a lembrança vem até ele, ele passa a adotar uma posição mais receptiva, de acolhimento da experiência encarnada.

A produção do gesto inicial de suspensão também varia. Na visão estereoscópica ela 
pode ser por uma atitude corporal ou pela resistência à conclusão da tarefa. Na Samatha, pode ser produzida por uma paralisação da fala, por uma mobilização individual, ou por uma atitude cognitiva prescrita. Além disso, Depraz, Varela e Vermersch (2003, 2006) também afirmam que a suspensão pode ser acionada por acontecimentos como o encontro com a morte de outrem ou a surpresa estética. Portanto, se estes autores enfatizam em tais exemplos a estrutura geral do ciclo básico, nós consideramos relevante enfatizar como o ciclo básico é acionado de forma diferente em contextos diferentes, dando ensejo a corporificações e experiências diferentes. E mesmo efeitos produtores de si diferentes. Existencialmente, não é a mesma coisa o praticante da oração do sagrado coração, da meditação budista, da psicanálise, da visão estereoscópica. Essa nossa ênfase é importante para não corrermos o risco de tomar o ciclo básico como uma representação objetiva, isolado de atores e/ou tradições concretas.

\section{Considerações Finais}

Como dizem Maturana e Varela (1995), todo conhecer humano pertence a um mundo próprio, é vivido dentro de uma tradição cultural (como é a própria tradição científica). Ao tentar conhecer o conhecer, acabamos por nos encontrar com nosso próprio ser. Ou seja, nos encontramos com a experiência, com as relações e as ações que nos constituem, dos quais advém o si e o mundo, mas, para os quais normalmente somos cegos. Por isso, o comprometimento a que somos levados a assumir com o conhecimento do conhecimento - reconhecer a imanência de nossos atos, que nossas certezas não são provas da verdade, que o mundo de cada um de nós não é o mundo, mas um mundo, que produzimos com outros. Daí a importância para os estudos da cognição de uma atenção à experiência, à maneira como o cognoscente corporifica a realidade conhecida, donde a proposta de Varela de inclusão de metodologias de primeira pessoa pelas ciências cognitivas. Mas, a inclusão dessas metodologias não pode se furtar à circularidade fundamental.

A importância e vivacidade da abordagem pragmática da fenomenologia de Depraz, Varela e Vermersch (2003, 2006) está no reencantamento do concreto que ela pressupõe, onde se descobre o que se relaciona com a questão a partir de sua práxis, de modo inseparável da sua efetuação ou enação. É neste sentido que a exploração da experiência, através de metodologias de primeira pessoa, é inseparável da própria experiência:

\footnotetext{
Todas as asserções budistas (falta de eu, o surgimento codependente da experiência da experiência, e outros) são tratadas pelos mestres budistas como descobertas, não como crenças ou doutrinas. Os mestres budistas gostam de ressaltar que os estudantes são sempre convidados, na verdade exigidos, a duvidar de tais asserções e verificá-las diretamente em sua própria experiência, em vez de aceitá-las como crenças. (VARELA; THOMPSON; ROSCH, 1992, p. 57, grifos nossos)
}

Assim, buscamos demonstrar que a discussão sobre metodologias de primeira pessoa, tal como toda atividade de conhecimento, não é apenas epistemológica, mas é, sobretudo, ontológica. As metodologias de primeira pessoa também são elas mesmas uma experiência, são práticas enativas e não representacionais. Como dissemos, isso nos impõe o desafio de avaliar o conhecimento não pela sua objetividade, mas sim pelas formas concretas e encarnadas que ele pode assumir, - que coloca para nós uma questão éticopolítica (VARELA, 1996b). É dessa maneira que devemos avaliar os efeitos constitutivos de si da prática do devir consciente, assim como a recusa do introspeccionismo clássico, e a mudança da experiência cotidiana de um eu sólido promovida pela meditação budista.

\section{Referências}

CHALMERS, D. O Enigma da Consciência. Scientific American Brasil Especial, São Paulo, n. 23, p. 40-49, 2004.

DEPRAZ, N. The Phenomenological Reduction as Praxis. J ournal of Consciousness Studies, Exeter, v. 6, n. 2/3, p. 95-110, 1999

DEPRAZ, N.; VARELA, F.; VERMERSCH, P. On Becoming Aware. Amsterdam: John Benjamins, 2003. 
DEPRAZ, N.; VARELA, F.; VERMERSCH, P. A Redução à Prova da Experiência. Arquivos Brasileiros de Psicologia, Rio de Janeiro, v. 58, n. 1, p. 75-86, 2006.

DESPRET, V. Hans, le cheval qui savait compter. Paris: Les empêcheurs de penser en Rond-Seuil, 2004.

JACK, A.; ROEPSTORFF, A. Introspection and Cognitive Brain mapping: from stimulus-response to scriptreport. Trends in Cognitive Sciences, v. 6, n. 8, p. 333-339, aug. 2002.

JACK, A.; ROEPSTORFF, A. Why trust the subject? Journal of Consciousness Studies, Exeter, v. 10, n. 9/10, p. $\mathrm{V}-\mathrm{XX}, 2003$.

JACK, A.; ROEPSTORFF, A. Trust or Interaction?: editorial introduction. Journal of Consciousness Studies, Exeter, v. 11, n. 7/8, p. v-xxii, 2004

KASTRUP, V. A Aprendizagem da Atenção na Cognição Inventiva. Psicologia e Sociedade, Belo Horizonte, v. 16, n. 3, p. 7-16, set./dez. 2004

LUTZ, A.; THOMPSON, E. Neurophenomenology: integrating subjective experience and brain dynamics in the neuroscience of consciousness. Journal of Consciousness Studies, Exeter, v. 10, n. 9-10, p. 31-52, 2003.

LUTZ, A; LACHAUX, J.P. et al. Guiding the study of brain dynamics by using first-person data: synchrony patterns correlate with ongoing conscious states during a simple visual task. Proceedings of the National Academy of Sciences USA, Washington, DC, v. 99, n. 3, p. 1586-1591, feb. 2002

mAtURANA, H.; VARELA, F. A Árvore do Conhecimento. Campinas: Ed. Psy, 1995.

NAGEL, T. What is it like to be a bat? In: HOFSTADTER, D.; DENNETT, D. The Mind's I. New York: Basic Books, 1981.

PETITMENGIN-PEUGEOT, C. The Intuitive Experience. Journal of Consciousness Studies, Exeter, v. 6, n. 2/3, p. 43-77, 1999

PETITMENGIN-PEUGEOT, C. Describing one's subjective experience in the second person: an interview method for the science of consciousness. Phenomenology and the Cognitive Sciences, Heidelberg, v. 5, n. 3/4, p. 229269, dec. 2006.

THOMPSON, E. The mindful body: embodiment and cognitive science. In: O'DONOVAN-ANDERSON, M. (Ed.). The Incorporated Self: interdisciplinary perspectives on embodiment. New York: Rowman \& Littlefield, 1996. P. 127-144.

THOMPSON, E. Life and mind: from Autopoiesis to Neurophenomenology: A tribute to Francisco Varela. Phenomenology and the Cognitive Sciences, Heidelberg, v. 3, n. 4, p. 381-398, 2004.

THOMPSON, E.; LUTZ, A.; COSMELLI, D. Neurophenomenology: an introduction for neurophilosophers. In: BROOK, A; AKINS, K. (Ed.). Cognition and the Brain: the Philosophy and Neuroscience Movement. Cambridge: Cambridge University Press, p. 40-97, 2005.

VARELA, F. Conhecer: as ciências cognitivas tendências e perspectivas. Lisboa: Instituto Piaget, 1988.

VARELA, F. Autonomie et connaissance. Paris: Seuil, 1989.

VARELA, F. Organism: A meshwork of selfless selves. In: TAUBER, A. Organism and the origins of self. Netherlands: Kluwer, p. 79-107, 1991. 
VARELA, F. The reenchantment of the concrete. Revista Zone, Cambridge, n. 6, p. 320-338, 1992.

VARELA, F. Neurophenomenology: a methodological remedy for the hard problem. Journal of Consciousness Studies, Exeter, v. 4, n. 3/4, p. 330-350, 1996a.

VARELA, F. Etica y Accion. Chile: Dolmen Ed., 1996b.

VARELA, F. Patterns of life: intertwining identity and cognition. Brain and Cognition, New York, n. 34, p. 72-87, 1997.

VARELA, F. O Cérebro Não é um Computador: não podemos entender a cognição se a abstrairmos de sua encarnação. La Recherche, Paris, n. 308, p. 109-112, 1998.

VARELA, F; SHEAR, J. First-person accounts: why, what, and how. Journal of Consciousness Studies, Exeter, v. 6, n. 2/3, p. 1-14, 1999.

VARELA, F.; THOMPSON, E.; ROSCH, E. De cuerpo presente. Barcelona: Editorial Gedisa, 1992. (Livro publicado em português: A Mente Incorporada: Ciências Cognitivas e Experiência Humana. Porto Alegre: Artmed, 2003).

VELMANS, M. Intersubjective science. Journal of Consciousness Studies, Exeter, v. 6, n. 2/3, p. 299-306, 1999.

VERMERSCH, P. L'entretien d'explicitation. Issy-les-moulineaux : ESF Éd., 1994.

VERMERSCH, P. La référence à l'expérience subjective. Alter : revue phénoménologique, Paris, n. 5, p. 121$136,1997$.

VERMERSCH, P. Introspection as Practice. Journal of Consciousness Studies, Exeter, v. 6, n. 2/3, p. 17-42, 1999.

VERMERSCH, P. Prende en compte la phénoménalité. Expliciter : journal de l'association GREX, Paris, n. 57, p. 35-46, dez. 2004.

WALLACE, A.B. The Buddhist tradition of samatha. Journal of Consciousness Studies, Exeter, v. 6, n. 2/3, p. 175-187, 1999.

WALLACE, A.B. A Revolução da Atenção: revelando o poder da mente focada. Petropólis: Vozes, 2008.

Recebido em agosto de 2009

Aprovado para publicação em setembro de 2009

\section{Christian Sade}

Professor do curso de Psicologia da Universidade Salgado de Oliveira (UNIVERSO) - email: christiansadevas@ yahoo.com.br 